\title{
Review \\ The human exosome: an autoantigenic complex of exoribonucleases in myositis and scleroderma
}

\author{
Rick Brouwer, Ger J M Pruijn and Walther J van Venrooij
}

Department of Biochemistry, University of Nijmegen, Nijmegen, The Netherlands

Correspondence: Dr W J van Venrooij, Department of Biochemistry, University of Nijmegen, PO Box 9101, NL-6500 HB, Nijmegen, The Netherlands. Tel: +31 24 3613656; fax: +31243540525; e-mail: w.vanvenrooij@bioch.kun.nl

Received: 1 November 2000

Revisions requested: 17 November 2000

Revisions received: 20 November 2000

Accepted: 22 November 2000

Published: 20 December 2000
Arthritis Res 2001, 3:102-106

(C) BioMed Central Ltd on behalf of the copyright holder (Print ISSN 1465-9905; Online ISSN 1465-9913)

\begin{abstract}
The anti-PM/Scl autoantibodies are known to characterize a subset of autoimmune patients with myositis, scleroderma (Scl), and the $\mathrm{PM} / \mathrm{Scl}$ overlap syndrome. The major autoantigens that are recognized by anti-PM/Scl autoantibodies are designated $\mathrm{PM} / \mathrm{Scl}-100$ and $\mathrm{PM} / \mathrm{Scl}-75$. These autoantigens have been reported to associate into a large complex consisting of 11 to 16 proteins and to play a role in ribosome synthesis. Recently, it was discovered that the PM/Scl complex is the human counterpart of the yeast (Saccharomyces cerevisiae) exosome, which is an RNA-processing complex consisting of $113^{\prime} \rightarrow 5^{\prime}$ exoribonucleases. To date, 10 human exosome components have been identified, although only some of these were studied in more detail. In this review, we discuss some recent advances in the characterization of the $\mathrm{PM} / \mathrm{Scl}$ complex.
\end{abstract}

Keywords: autoantibodies, autoantigens, exoribonucleases, exosome, PM/Scl complex

\section{Introduction}

Autoantibodies are the hallmark of many autoimmune disorders, such as the connective-tissue diseases scleroderma, systemic lupus erythematosus, Sjögren's syndrome, idiopathic inflammatory myopathies (IIMs), rheumatoid arthritis, and mixed connective-tissue disease. Although their etiology and pathogenic role remain unclear, many different autoantibody specificities have been characterized. Some of these autoantibodies are very useful as diagnostic markers and may also have a prognostic value, as has been shown for anti-doublestranded-DNA antibodies in systemic lupus erythematosus and anti-cyclic-citrullinated-peptide antibodies in rheumatoid arthritis $[1,2]$. Other autoantibodies have proved to be valuable tools to study cellular processes in which the autoantigens are involved, such as the splicing of precursor messenger RNAs (pre-mRNAs) mediated by the autoantigenic $\mathrm{U}$ small nuclear ribonucleoprotein com- plexes (U snRNPs) [3]. Similarly, autoantibodies directed to a protein complex, known as the polymyositis-scleroderma (PM/Scl) complex, have contributed to the discovery of a large RNA-processing complex, which is now known as the human exosome.

Here we present an overview of recent studies that have led to the current biochemical and functional understanding of the PM/Scl complex.

\section{Clinical characteristics of patients positive for anti-PM/Scl autoantibodies}

The anti-PM/Scl autoantibody, formerly known as antiPM-1 [4], may be detected in sera of patients with myositis, scleroderma, and PM/Scl overlap syndrome, although some patients positive for anti-PM/Scl autoantibodies may not have either of these conditions [5,6]. The patient group positive for anti-PM/Scl antibodies is characterized

IIM = idiopathic inflammatory myopathy; PM/Scl = polymyositis/scleroderma; pre-mRNA = precursor mRNA; Rrp = ribosomal RNA processing; snRNA = small nuclear RNA; snoRNA = small nucleolar RNA; U snRNP = U small nuclear ribonucleoprotein. 
by an elevated incidence of Raynaud's phenomenon, arthritis, pulmonary disease, and calcinosis $[7,8]$. In general, patients positive for anti-PM/Scl antibodies respond well to immunosuppressive therapy and have a good prognosis $[5,7,8]$. In contrast to the findings in large North American and European cohort studies, the PM/Scl autoantibody was not detected in sera of Japanese patients with inflammatory muscle disease, which suggests that specific environmental or genetic factors are involved in the induction of this autoantibody response [9-12]. Indeed, an assessment of the HLA-DR genotypes of anti-PM/Scl-positive patients revealed a $75-100 \%$ correlation with HLA-DR3 $[7,13,14]$.

\section{The autoantigenic PM/Scl complex}

The complex that is recognized by the anti-PM/Scl autoantibody has a sedimentation coefficient of $20 \mathrm{~S}$ as determined by sucrose-gradient centrifugation and was reported to consist of 11 to 16 proteins [15-17]. Proteins identified in these studies had molecular masses ranging from 110 to $20 \mathrm{kDa}$ in SDS-PAGE $[16,17]$. Inconsistent data were reported with respect to the phosphorylation of some components $[4,16,17]$.

Western blot analyses of patient sera positive for the anti$\mathrm{PM} / \mathrm{Scl}$ autoantibody revealed that the major autoantigen is the 110-kDa protein (PM/Scl-100), although some sera also recognized the $80-\mathrm{kDa}$ protein (PM/Scl-75) $[16,17]$. Two cDNA clones encoding possible splicing variants of the PM/Scl-100 autoantigen have been isolated and characterized [18,19]. The PM/Scl-100 autoantigen contains several linear epitopes, but the major epitope is located in the $\mathrm{N}$-terminal region (amino acid residues 232-241) [20]. The other autoantigenic component of the PM/Scl complex, PM/Scl-75, was shown to be a protein with a predicted molecular mass of $39 \mathrm{kDa}$. Its very acidic C-terminal tail probably accounts for the aberrant migration of this protein in SDS-PAGE [21]. Recognition of the PM/Scl-75 autoantigen by autoantibodies is primarily dependent on this C-terminal region (amino acid residues 196-355) [21].

Immunolocalization studies showed that the $\mathrm{PM} / \mathrm{Scl}$ autoantigens are present in the nucleoplasm and, at higher concentrations, in the nucleolus $[16,17,22]$. Like other nuclear substructures, the nucleolus is not separated from the nucleoplasm by a membrane, and its formation is presumably the result of local accumulation of numerous functionally related factors $[23,24]$. The nucleolus is the site of ribosome synthesis, which involves the transcription and nucleolytic processing of precursor rRNAs, the nucleotide modification of rRNAs, and the assembly of mature rRNAs with approximately 80 ribosomal proteins into small and large ribosomal subunits [23,24]. Electron microscopy reveals that the $\mathrm{PM} / \mathrm{Scl}$ autoantigens are predominantly localized in the granular compartment of the nucleolus, which is the site of ribosome assembly [17]. Inhibition of
rRNA transcription by actinomycin D resulted in the nucleoplasmic rather than nucleolar accumulation of the $\mathrm{PM} / \mathrm{Scl}$ autoantigens, a finding that also supports the idea that $\mathrm{PM} / \mathrm{Scl}$ autoantigens play a role in ribosome synthesis [17].

Except for some similarity with members of the serine/threonine protein kinase family [18], very limited functional information could be deduced from the polypeptide sequence of the $\mathrm{PM} / \mathrm{Scl}$ autoantigens at the time of cloning $[18,19,21]$. However, more recent sequence analyses revealed that $\mathrm{PM} / \mathrm{Scl}-100$ and -75 are homologous to RNA-degrading enzymes of Escherichia coli, namely the $3^{\prime} \rightarrow 5^{\prime}$ exoribonucleases $\mathrm{D}$ and $\mathrm{PH}$ (RNase D and RNase $\mathrm{PH}$ ), respectively [25].

\section{A multi-subunit complex of $3^{\prime} \rightarrow 5^{\prime}$ exoribonucleases has been identified in yeast} In yeast (Saccharomyces cerevisiae), 11 proteins, 10 of which are known or predicted to have $3^{\prime} \rightarrow 5^{\prime}$ exoribonuclease activity, were purified as a single complex that is referred to as 'the exosome' $[26,27]$. Ten components are essential for yeast viability (Rrp4p, Rrp40-46p, Mtr3p, and Cs(4p); one component, Rrp6p, is nonessential, although deletion of the RRP 6 gene leads to impaired growth and temperature sensitivity $[26,28]$. As summarized in Table 1, homologues for most of the components have been identified in E. coli and humans. Notably, two yeast exosome components, namely Rrp6p and Rrp45p, are homologous to the $\mathrm{PM} / \mathrm{Scl}-100$ and $\mathrm{PM} / \mathrm{Scl}-75$ autoantigens, respectively (see also below).

To date, no structural data have been presented, although two speculative models for the organization and activation of the exosome subunits have recently been proposed $[29,30]$. Several lines of evidence suggest that at least two different exosomes exist [26]. First, the 10 essential components were purified with apparent stoichiometry, while approximately one-fifth as much Rrp6p was recovered. Second, two complexes, only one of them containing the Rrp6 protein, could be recovered from fractionated wholecell extracts. Third, no cytoplasmic Rrp6p could be detected by immunolocalization, in contrast to the nuclear and cytoplasmic presence of Rrp4p and Rrp43p [26,31]. Finally, functional studies, as described below, suggest the existence of a cytoplasmic and nuclear exosome complex. Together, these data indicate that the yeast exosome is present in the nuclear and cytoplasmic compartments and that these complexes differ by the presence or absence of Rrp6p, the yeast homologue of PM/Scl-100.

\section{Functions of the yeast exosome}

The most important experimental approach to determining the functions of the exosome encompassed RNA analyses of yeast strains that were deficient for one or more components of the exosome. Conditional mutants were created 
Table 1

\begin{tabular}{|c|c|c|c|}
\hline Yeast & Escherichia coli & Human & Comments \\
\hline $\operatorname{Rrp} 4 p$ & S1 RNA-binding domain & hRrp4p & $\begin{array}{l}\text { Interaction with } \mathrm{PM} / \mathrm{Scl} \text { autoantigens; } \mathrm{hRrp} 4 \mathrm{p} \text { is a } \\
\text { functional homologue of the yeast component }\end{array}$ \\
\hline Rrp40p & S1 RNA-binding domain & hRrp40p & Interaction with $\mathrm{PM} / \mathrm{Scl}$ autoantigens \\
\hline Rrp41p/Ski6p & RNase PH & hRrp41p & $\begin{array}{l}\text { Interaction with } \mathrm{PM} / \mathrm{Scl} \text { autoantigens; } \mathrm{h} \operatorname{Rrp} 41 \mathrm{p} \text { is a } \\
\text { functional homologue of the yeast component }\end{array}$ \\
\hline Rrp42p & RNase $\mathrm{PH}$ & hRrp42p & Partial human cDNA clone (D29958) \\
\hline Rrp43p & RNase $\mathrm{PH}$ & No clear homologue & \\
\hline Rrp44p/Dis3p & RNase R & hRrp44p/hDis3p & $\mathrm{hRrp} 44 \mathrm{p}$ is a functional homologue of the yeast component \\
\hline \multirow[t]{2}{*}{ Rrp45p } & RNase $\mathrm{PH}$ & $\mathrm{PM} / \mathrm{Scl}-75$ & Interaction with hRrp4p \\
\hline & & OIP $2 p$ & Partial human cDNA clone \\
\hline Rrp46p & RNase PH & hRrp46p & Interaction with $\mathrm{PM} / \mathrm{Scl}$ autoantigens \\
\hline Rrp6p & RNase D & $\mathrm{PM} / \mathrm{Scl}-100$ & Interaction with $\mathrm{hRrp} 4 \mathrm{p}$, only present in nucleus \\
\hline Mtr3p & RNase $\mathrm{PH}$ & No clear homologue & \\
\hline Csi4p/Ski4p & S1 RNA-binding domain & $\mathrm{hCs} \mid 4 \mathrm{p}$ & $h C s \mid 4 p$ is a functional homologue of the yeast component \\
\hline
\end{tabular}

Adapted from [26].

for the essential genes, whereas the nonessential RRP6 gene was disrupted. In general, the accumulation of a particular RNA in a mutant yeast strain suggests that this molecule is the substrate for the depleted component, whereas a reduction indicates that the RNA is a product generated by the depleted component. Such analyses revealed that the yeast exosome is involved in the processing and degradation of several RNA species.

The first function assigned to the exosome was its role in rRNA processing. In the nucleolus, four RNA molecules (5S, 5.8S, 18S, and 25S rRNA) and many proteins associate into ribosomes [32]. Three rRNAs (5.8S, 18S, and 25S rRNA) are transcribed as a large, 35S precursor rRNA, which is processed via a cascade of endo- and exonucleolytic cleavages into the mature rRNAs. Yeast strains that were mutated in any of the exosome components showed multiple defects in the maturation of this large precursor RNA. One of these defects is indirect inhibition of early endonucleolytic precursor rRNA cleavages [31,33,34]. Another is ineffective final $3^{\prime}$-end processing of the $5.8 \mathrm{~S}$ rRNA [26-28,33-36]. Third, a noncoding spacer RNA (the $5^{\prime}$ external transcribed spacer) and some aberrant rRNA species that arise from the inhibited early endonucleolytic precursor rRNA cleavages are stabilized [26,33,34,36].

The function of the exosome is not restricted to the maturation of rRNA. The $3^{\prime}$ processing of small nuclear RNAs that play a role in precursor messenger RNA splicing (the U1, U2, U4, and U5 snRNAs) or in the processing and modification of rRNA (small nucleolar RNAs; eg U3, U14, U18, and U24 small nucleolar RNA [snoRNA]) is also hampered in mutant exosome strains [36-38]. Moreover, the exosome has been shown to compete with the splicing apparatus for unspliced nuclear mRNAs in order to degrade these premRNAs $[39,40]$. The cytoplasmic exosome subfraction is probably involved in the degradation of mature cytoplasmic mRNAs, since mutations in the RRP4 and RRP41 genes inhibited $3^{\prime} \rightarrow 5^{\prime}$ mRNA decay [41].

\section{The PM/Scl complex is the human exosome}

Characterization of the yeast exosome has greatly enhanced our current knowledge of the human $\mathrm{PM} / \mathrm{Scl}$ complex. At present, a number of studies have provided evidence that this complex, as schematically represented in Fig. 1, is the human counterpart of the yeast exosome, thus consisting of multiple $3^{\prime} \rightarrow 5^{\prime}$ exoribonucleases.

In one study, analysis of the composition of the yeast exosome led to the identification of two components, Rrp6p and Rrp45p, that are homologous to the human $\mathrm{PM} / \mathrm{Scl}-100$ and PM/Scl-75 autoantigens, respectively [26]. To date, 10 human homologues have been identified for the yeast exosome components, as listed in Table 1 $[18,19,21,26,35,42-45]$. No homologues were found for Rrp43p and Mtr3p, whereas two human proteins (PM/Scl-75 and OIP2p) were the most homologous with Rrp45p [26]. Since the PM/Scl complex was reported to consist of 11 to 16 proteins, additional human components may remain to be identified $[16,17]$. Conclusive data for a physical association with the PM/Scl autoantigens have been provided for hRrp4p, hRrp40p, hRrp41p, and hRrp46p by co-immunoprecipitation and cosedimentation experiments $[26,45]$. 
Figure 1

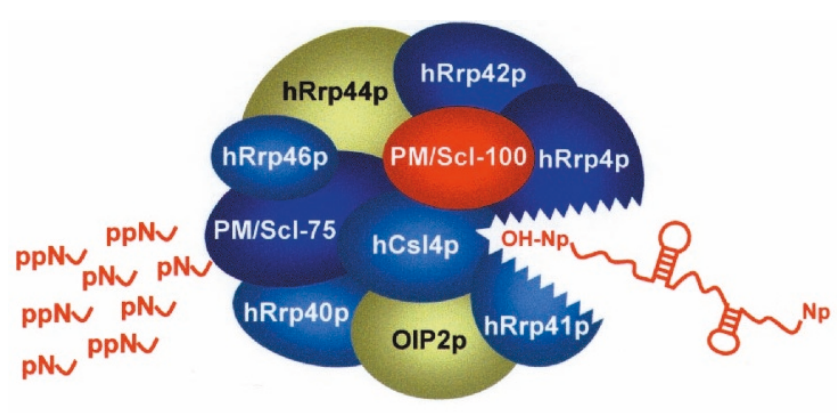

Schematic representation of the human exosome complex. The associations between individual components of the human exosome are hypothetical, since no structural data have been presented to date. All human exosome components analyzed so far (PM/Scl-100, PM/Scl75, hRrp4p, hRrp40p, hRrp41p, hRrp42p, hRrp46p, and hCs|4p) are recognized by autoantibodies present in IIM sera, although some (PM/Scl-100, PM/Scl-75, and hRrp4p) are preferentially recognized.

The size of the yeast exosome, its nuclear localization with nucleolar enrichment, and its role in rRNA processing correspond well to the properties that were previously suggested for the PM/Scl complex $[16,17,22,46]$. Indeed, more detailed characterization of the novel human components confirmed that some of the properties found for the yeast exosome also apply for the PM/Scl complex, or the human exosome. First, the human exosome was shown to exhibit $3^{\prime} \rightarrow 5^{\prime}$ exoribonuclease activity. Four human homologues (hRrp4p, hRrp41p, hRrp44p/hDis3p, and hCsl4p) were able to suppress the growth defects of yeast strains that were caused by mutations in the corresponding yeast genes, indicating that these proteins are functionally conserved $[35,42,43,45]$. In addition, complexes that were precipitated from HeLa-cell extract using either rabbit antisera specific for hRrp40p and hRrp46p or a serum from a patient positive for anti-PM/Scl autoantibodies exhibit $3^{\prime} \rightarrow 5^{\prime}$ exoribonuclease activity in vitro [45].

As in yeast, at least two forms of the human exosome, which can be distinguished by the presence or absence of $\mathrm{PM} / \mathrm{Scl}-100$ (the homologue of Rrp6p), are likely to exist. This conclusion is mainly supported by studies that determined the subcellular distribution of hRrp4p, hRrp40p, hRrp41p, hRrp46p, and the PM/Scl autoantigens by HeLa-cell fractionation $[26,45]$. As in the yeast exosome, the analyzed components, except PM/Scl-100, were clearly detected in both cytoplasmic and nuclear extracts. $\mathrm{PM} / \mathrm{Scl}-100$, in contrast, was mainly present in the saltextractable nuclear fraction, which is in accord with the previous observations made with patients' autoimmune sera that predominantly recognize this antigen [16-19]. On the basis of the subcellular distribution, it may be speculated that both nuclear and cytoplasmic functions of the exosome have been conserved during evolution.

\section{Autoantibodies directed against components of the human exosome}

Approximately $5-8 \%$ of the sera from myositis patients, $3 \%$ of those from scleroderma patients, and $24 \%$ of those from patients with $\mathrm{PM} / \mathrm{Scl}$ overlap syndrome contain the anti$\mathrm{PM} / \mathrm{Scl}$ autoantibody $[5,9,46,47]$. The autoantibodies that characterize this specificity are predominantly directed against the PM/Scl-100 antigen, whereas approximately $50-60 \%$ of the sera positive for anti-PM/Scl contain autoantibodies directed against the PM/Scl-75 antigen as well $[9,16,17,48]$. Novel components of the human exosome (hRrp4p, hRrp40p, hRrp41p, hRrp42p, hRrp46p, and $\mathrm{hCs}(4 \mathrm{p})$ are also targeted by autoantibodies and some are preferentially recognized [45]. In anti-PM/Scl-positive IIM sera, the prevalences of the anti-hRrp4p autoantibody and the anti-PM/Scl-75 autoantibody are similar (approximately 54\%), but are not correlated [45]. These results further support the hypothesis that the autoimmune response may initially be directed against the $\mathrm{PM} / \mathrm{Scl}-100$ antigen, whereas intermolecular epitope spreading may be responsible for the autoantibody response directed against the other, associated antigens. To date, the mechanism that triggers the initial autoantibody response is not known, but it could involve defective apoptosis (reviewed in [49]).

\section{Concluding remarks}

Taken together, the data reviewed here indicate that the human $\mathrm{PM} / \mathrm{Scl}$ complex closely resembles the yeast exosome in both composition and function and therefore may be referred to as 'the human exosome'. However, further studies are needed to support the functional homology between the yeast and human complexes.

As the physiological role and composition of the human exosome become clear, one challenge will be to establish how and why this intracellular complex is targeted by autoantibodies in patients with IIM. All the components of the human exosome analyzed so far are recognized by autoantibodies present in IIM sera, although PM/Scl-100 remains the most important target. The identification and characterization of novel components of the $\mathrm{PM} / \mathrm{Scl}$ complex offers the possibility of investigating the autoantibody response in more detail.

\section{References}

1. von Muhlen CA, Tan EM: Autoantibodies in the diagnosis of systemic rheumatic diseases. Semin Arthritis Rheum 1995, 24 : 323-358.

2. Schellekens $G A$, Visser $H$, de Jong BAW, van den Hoogen $F H J$, Hazes JMW, Breedveld FC, van Venrooij WJ: The diagnostic properties of rheumatoid arthritis antibodies recognizing a cyclic citrullinated peptide. Arthritis Rheum 2000, 43:155-164.

3. Klein Gunnewiek JMT, van de Putte LB, van Venrooij WJ: The U1 snRNP complex: an autoantigen in connective tissue diseases. An update. Clin Exp Rheumatol 1997, 15:549-560.

4. Wolfe JF, Adelstein E, Sharp GC: Antinuclear antibody with distinct specificity for polymyositis. J Clin Invest 1977, 59:176-178.

5. Oddis CV, Okano Y, Rudert WA, Trucco M, Duquesnoy RJ, Medsger TAJ: Serum autoantibody to the nucleolar antigen PM-Scl. Clinical and immunogenetic associations. Arthritis Rheum 1992, 35:1211-1217. 
6. Schnitz W, Taylor AE, Targoff IN, Reichlin M, Scofield RH: Anti$\mathrm{PM} / \mathrm{Scl}$ autoantibodies in patients without clinical polymyositis or scleroderma. J Rheumatol 1996, 23:1729-1733.

7. Marguerie C, Bunn CC, Copier J, Bernstein RM, Gilroy JM, Black $\mathrm{CM}$, So AK, Walport MJ: The clinical and immunogenetic features of patients with autoantibodies to the nucleolar antigen PM-Scl. Medicine Baltimore 1992, 71:327-336.

8. Jablonska S, Blaszczyk M: Scleromyositis: A scleroderma/polymyositis overlap syndrome. Clin Rheumatol 1998, 17:465-467.

9. Brouwer R, Hengstman GJD, Vree Egberts WTM, Ehrfeld H, Bozic B, Ghirardello A, Grondal G, Hietarinta M, Isenberg D, Kalden JR, Lundberg I, Moutsopoulos H, Roux-Lombard P, Vencovsky J, Wikman A, Seelig HP, van Engelen BGM, van Venrooij WJ: Autoantibody profiles in sera of European myositis patients. Ann Rheum Dis 2001, in press.

10. Love LA, Leff RL, Fraser DD, Targoff IN, Dalakas M, Plotz PH, Miller FW: A new approach to the classification of idiopathic inflammatory myopathy: myositis-specific autoantibodies define useful homogeneous patient groups. Medicine Baltimore 1991, 70:360-374.

11. Arnett FC, Targoff IN, Mimori T, Goldstein R, Warner NB, Reveille JD: Interrelationship of major histocompatibility complex class II alleles and autoantibodies in four ethnic groups with various forms of myositis. Arthritis Rheum 1996, 39:1507-1518.

12. Hirakata $M$, Mimori T, Akizuki M, Craft J, Hardin JA, Homma M: Autoantibodies to small nuclear and cytoplasmic ribonucleoproteins in Japanese patients with inflammatory muscle disease. Arthritis Rheum 1992, 35:449-456.

13. Genth E, Mierau R, Genetzky P, von Muhlen CA, Kaufmann S, von-Wilmowsky H, Meurer M, Krieg T, Pollmann HJ, Hartl PW: Immunogenetic associations of scleroderma-related antinuclear antibodies. Arthritis Rheum 1990, 33:657-665.

14. Hausmanowa-Petrusewicz I, Kowalska OE, Miller FW, Jarzabek CM, Targoff IN, Blaszczyk KM, Jablonska S: Clinical, serologic, and immunogenetic features in Polish patients with idiopathic inflammatory myopathies. Arthritis Rheum 1997, 40:1257-1266.

15. Bautz FA, Bluthner M: The PM/Scl antigens. In Manual of biological markers of disease. Edited by van Venrooij WJ, Maini RN. Dordrecht: Kluwer Academic Publishers, 1994: B5.4/1-B5.4/17.

16. Gelpi C, Alguero A, Angeles MM, Vidal S, Juarez C, Rodriguez SJ: Identification of protein components reactive with anti-PM/Scl autoantibodies. Clin Exp Immunol 1990, 81:59-64.

17. Reimer G, Scheer U, Peters JM, Tan EM: Immunolocalization and partial characterization of a nucleolar autoantigen (PM$\mathrm{Scl})$ associated with polymyositis/scleroderma overlap syndromes. J Immunol 1986, 137:3802-3808.

18. Bluthner M, Bautz FA: Cloning and characterization of the cDNA coding for a polymyositis-scleroderma overlap syndromerelated nucleolar 100-kD protein. J Exp Med 1992, 176:973-980.

19. Ge $\mathrm{O}$, Frank MB, O'Brien C, Targoff IN: Cloning of a complementary DNA coding for the $100-\mathrm{kD}$ antigenic protein of the PM-Scl autoantigen. J Clin Invest 1992, 90:559-570.

20. Bluthner M, Mahler M, Muller DB, Dunzl H, Bautz FA: Identification of an alpha-helical epitope region on the $\mathrm{PM} / \mathrm{Scl}-100$ autoantigen with structural homology to a region on the heterochromatin p25-beta autoantigen using immobilized overlapping synthetic peptides. $J$ Mol Med 2000, 78:47-54.

21. Alderuccio F, Chan EK, Tan EM: Molecular characterization of an autoantigen of $\mathrm{PM}-\mathrm{Scl}$ in the polymyositis/scleroderma overlap syndrome: a unique and complete human cDNA encoding an apparent 75-kD acidic protein of the nucleolar complex. J Exp Med 1991, 173:941-952.

22. Targoff IN, Reichlin M: Nucleolar localization of the PM-Scl antigen. Arthritis Rheum 1985, 28:226-230.

23. Scheer U, Hock R: Structure and function of the nucleolus. Curr Opin Cell Biol 1999, 11:385-390.

24. Carmo-Fonseca M, Mendes-Soares L, Campos I: To be or not to be in the nucleolus. Nature Cell Biol 2000, 2:E107-E112.

25. Mian IS: Comparative sequence analysis of ribonucleases $\mathrm{HII}$, III, II PH and D. Nucleic Acids Res 1997, 25:3187-3195.

26. Allmang C, Petfalski E, Podtelejnikov A, Mann M, Tollervey D, Mitchell $\mathrm{P}$ : The yeast exosome and human $\mathrm{PM}-\mathrm{Scl}$ are related complexes of $3^{\prime} \rightarrow 5^{\prime}$ exonucleases. Genes Dev 1999, 13:2148-2158.

27. Mitchell P, Petfalski E, Shevchenko A, Mann M, Tollervey D: The exosome: a conserved eukaryotic RNA processing complex containing multiple $\mathbf{3}^{\prime} \rightarrow 5^{\prime}$ exoribonucleases. Cell 1997, 91 : 457-466.
28. Briggs MW, Burkard KT, Butler JS: Rrp6p, the yeast homologue of the human PM-Scl 100-kDa autoantigen, is essential for efficient 5.8 S rRNA 3' end formation. J Biol Chem 1998, 273: 13255-13263.

29. van Hoof A, Parker R: The exosome: A proteasome for RNA? Cell 1999, 99:347-350.

30. Mitchell P, Tollervey D: Musing on the structural organization of the exosome complex. Nat Struct Biol 2000, 7:843-846.

31. Zanchin NI, Goldfarb DS: Nip7p interacts with Nop8p, an essential nucleolar protein required for $60 \mathrm{~S}$ ribosome biogenesis, and the exosome subunit Rrp43p. Mol Cell Biol 1999, 19: $1518-1525$

32. Venema J, Tollervey D: Ribosome synthesis in Saccharomyces cerevisiae. Annu Rev Genet 1999, 33:261-311.

33. Allmang C, Mitchell P, Petfalski E, Tollervey D: Degradation of ribosomal RNA precursors by the exosome. Nucleic Acids Research 2000, 28:1684-1691.

34. Zanchin NI, Goldfarb DS: The exosome subunit Rrp43p is required for the efficient maturation of $5.8 S, 18 S$ and $25 S$ rRNA. Nucleic Acids Res 1999, 27:1283-1288.

35. Mitchell P, Petfalski E, Tollervey D: The $3^{\prime}$ end of yeast $5.8 \mathrm{~S}$ rRNA is generated by an exonuclease processing mechanism. Genes Dev 1996, 10:502-513.

36. Allmang C, Kufel J, Chanfreau G, Mitchell P, Petfalski E, Tollervey $D$ : Functions of the exosome in rRNA, snoRNA and snRNA synthesis. EMBO J 1999, 18:5399-5410.

37. van Hoof $A$, Lennertz $P$, Parker R: Yeast exosome mutants accumulate 3'-extended polyadenylated forms of U4 small nuclear RNA and small nucleolar RNAs. Mol Cell Biol 2000, 20:441-452.

38. Kufel J, Allmang C, Chanfreau G, Petfalski E, Lafontaine DJL, Tollervey $D$ : Precursors to the U3 snoRNA lack snoRNP proteins but are stabilized by La binding. Mol Cell Biol 2000, 20:5415-5424.

39. Burkard KTD, Butler JS: A nuclear $3^{\prime}-5^{\prime}$ exonuclease involved in mRNA degradation interacts with poly $(A)$ polymerase and the hnRNA protein Npl3p. Mol Cell Biol 2000, 20:604-616.

40. Bousquet-Antonelli $C$, Presutti $C$, Tollervey D: Identification of a regulated pathway for nuclear pre-mRNA turnover. Cell 2000, 102:765-775.

41. Jacobs Anderson JS, Parker R: The $3^{\prime}$ to $5^{\prime}$ degradation of yeast mRNAs is a general mechanism for mRNA turnover that requires the SKI 2 DEVH box protein and $3^{\prime}$ to $5^{\prime}$ exonucleases of the exosome complex. EMBO J 1998, 17:1497-1506.

42. Baker RE, Harris $K$, Zhang K: Mutations synthetically lethal with cep1 target S. cerevisiae kinetochore components. Genetics 1998, 149:73-85.

43. Shiomi T, Fukushima K, Suzuki N, Nakashima N, Noguchi E, Nishimoto T: Human dis3p, which binds to either GTP- or GDP-Ran, complements Saccharomyces cerevisiae dis3. J Biochem Tokyo 1998, 123:883-890.

44. Williams JM, Chen GC, Zhu L, Rest RF: Using the yeast twohybrid system to identify human epithelial cell proteins that bind gonococcal Opa proteins: intracellular gonococci bind pyruvate kinase via their Opa proteins and require host pyruvate for growth. Mol Microbiol 1998, 27:171-186.

45. Brouwer R, Allmang C, Raymakers R, van Aarssen Y, Vree Egberts W, Petfalski E, van Venrooij WJ, Tollervey D, Pruijn GJM: Three novel components of the human exosome. J Biol Chem 2001 , in press.

46. Reimer G, Steen VD, Penning CA, Medsger-TA J, Tan EM: Correlates between autoantibodies to nucleolar antigens and clinical features in patients with systemic sclerosis (scleroderma). Arthritis Rheum 1988, 31:525-532.

47. Reichlin M, Maddison PJ, Targoff IN, Bunch T, Arnett F, Sharp G, Treadwell E, Tan EM: Antibodies to a nuclear/nucleolar antigen in patients with polymyositis overlap syndromes. J Clin Immunol 1984, 4:40-44.

48. Ge Q, Wu Y, Trieu EP, Targoff IN: Analysis of the specificity of antiPM-Scl autoantibodies. Arthritis Rheum 1994, 37:1445-1452.

49. Rodenburg RJT, Raats JMH, Pruijn GJM, van Venrooij WJ: Cell death: a trigger of autoimmunity? Bioessays 2000, 22:627-636. 